\title{
CFD Analysis of Wind-Driven Natural Ventilation in Building Models
}

\author{
Okafor Chinedu Vincent ${ }^{1}$, Okeke Arinze Uchenna ${ }^{1}$, Ononye Olisa Roy ${ }^{2}$ \\ ${ }^{1}$ Department of Building, Nnamdi Azikiwe University Awka, Nigeria \\ ${ }^{2}$ Department of Building Technology Education, Federal College of Education (Technical) Asaba, Nigeria
}

\begin{abstract}
This paper studied wind-driven natural ventilation in a room using computational fluid dynamics model in order to determine the airflow pattern, draft and pollutant dispersion within the CFD model. The different natural ventilation strategies were studied in cases namely: CASE 1(Single sided ventilation), CASE 2(Cross Ventilation), CASE 3(Bernoulli and Cross Ventilation) and CASE 4(Double single sided ventilation). The CFD simulation was performed with the $3 D$ steady state RANS approach using RNG-KE turbulent model to provide closure. From the result obtained, the author found out that Firstly, CASE 1 and CASE 4 showed a reduce level of air draft $(V<0.2 \mathrm{~m} / \mathrm{s})$ within the room unlike the CASE 2 and CASE 3 where the air speed on the room occupants most especially at the ankle and head region were much higher than that recommended as per BS EN 7730. Secondly, CASE 2 showed greater efficiency in dealing with pollutant dispersion then followed by CASE 3 and CASE 4 respectively. The CO${ }_{2}$ concentrations in almost every part of the room for CASE 2 were well within the acceptable range recommended for human occupancy as per BS EN 7730.
\end{abstract}

Key Words: Natural Ventilation, $\mathrm{CFD}, \mathrm{CO}_{2}$ dispersion, IAQ, Thermal comfort.

\section{INTRODUCTION}

Ventilation can be defined as a controlled replacement of stale room air with cool fresh air with an aim of improving the indoor air quality and thermal comfort within the occupied space. Ventilation is brought about either by mechanical means or natural means; in the mechanical means, large volume of air are moved around buildings by fan or air diffusers whereas, in the natural ventilation case, air is driven by wind effect, temperature difference between the internal and external air in the building or through buoyancy through cracks in the building envelope/purposely installed openings.

One of the arguments in natural ventilation is the fact that it can be difficult to control the amount of air going through the crack or openings. Therefore; it might be difficult to control the indoor air quality and thermal comfort within the building [1].

Mechanical ventilation on the other hand consumes large amount of energy when compared to natural ventilation [2]. The energy cost of a naturally ventilated building is $40 \%$ less than an air conditioned building [3] making natural ventilation an approach towards a sustainable and energy efficient built environment. Natural Ventilation is also a passive technology which helps us to reduce the damaging outlets to the environment and make the building independent on unused energy. Studies in natural ventilation has further shown that building occupants tend to report better satisfaction and less sick building syndrome when natural ventilation is employed than with mechanical ventilation[4,5]

However, it should be noted that Natural ventilation can only be applied to certain climates. Also, noise and pollution may limit the application of natural ventilation [6].

The aim in this study is to analyze the airflow pattern and $\mathrm{CO}_{2}$ distribution within naturally ventilated buildings using computational fluid dynamics.

Computational fluid dynamics has become one of the most important tools in studying building ventilation [7]. Computational fluid dynamics solves the conservation equation of mass, momentum and energy of flows. Analysing natural ventilations in buildings using in-situ measuring tools has proven to be uneconomical due to the cost, energy and time consuming process involved in taking readings at many locations thereby, making CFD modelling to become more and more attractive and popular in the design community [6]. Using computational fluid dynamics, engineers can decide ideal layout and openings for the best natural ventilation by modelling and simulating the actual phenomenon in full scale. 


\section{MODELLING}

The focus was to evaluate single sided ventilation, double single sided ventilation, cross ventilation and Bernoulli ventilation for a room that is $5.16 \mathrm{~m}$ long, $2.43 \mathrm{~m}$ wide and $3.65 \mathrm{~m}$ high. The general room model used throughout the study is shown below.

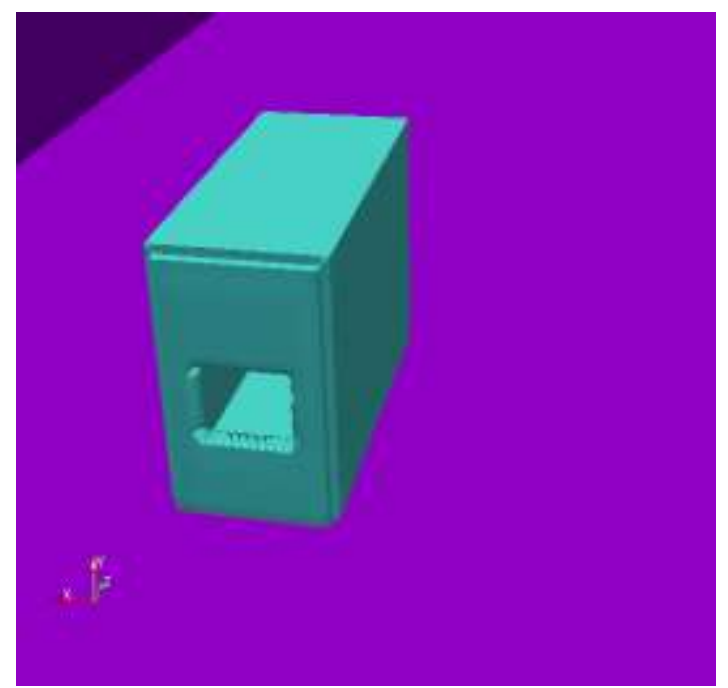

Figure 1: Case 1(Single sided ventilation)

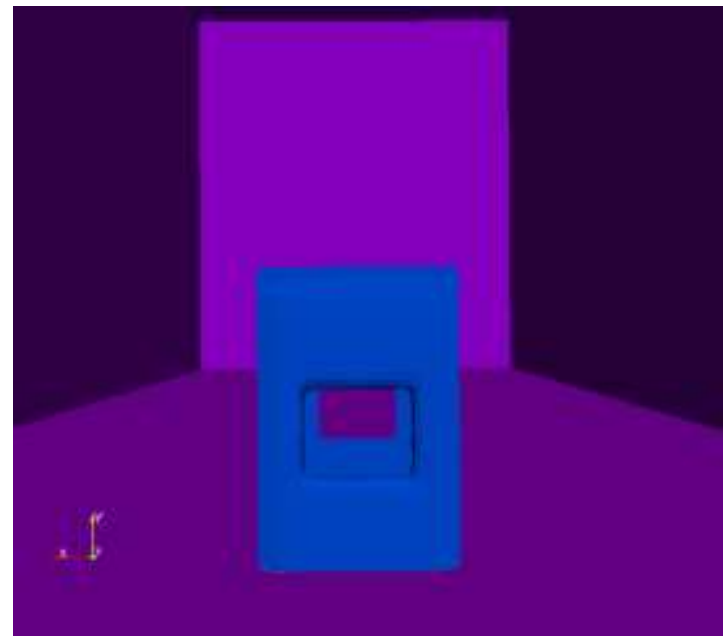

Figure 2: Case 2(Cross Ventilation)

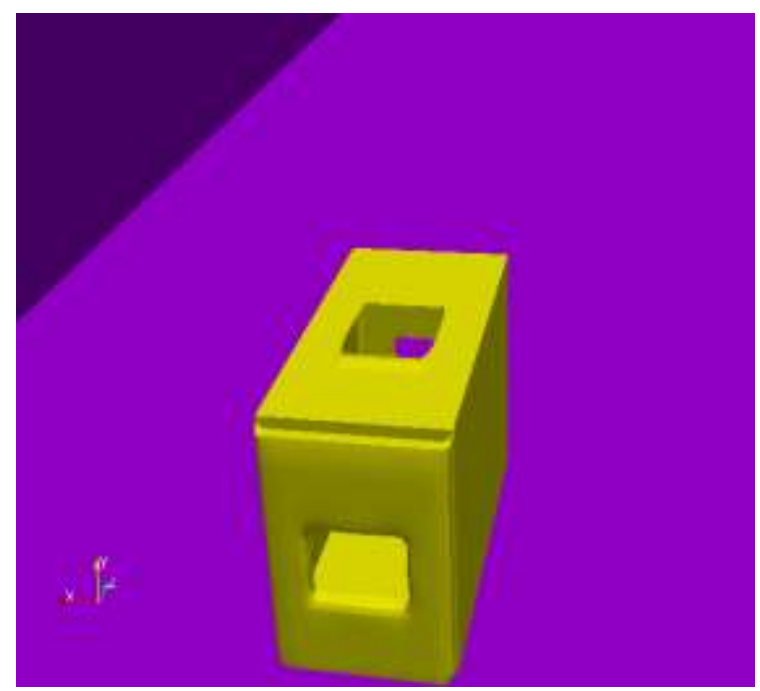

Figure 3: Case 3(Bernoulli and Cross Ventilation)

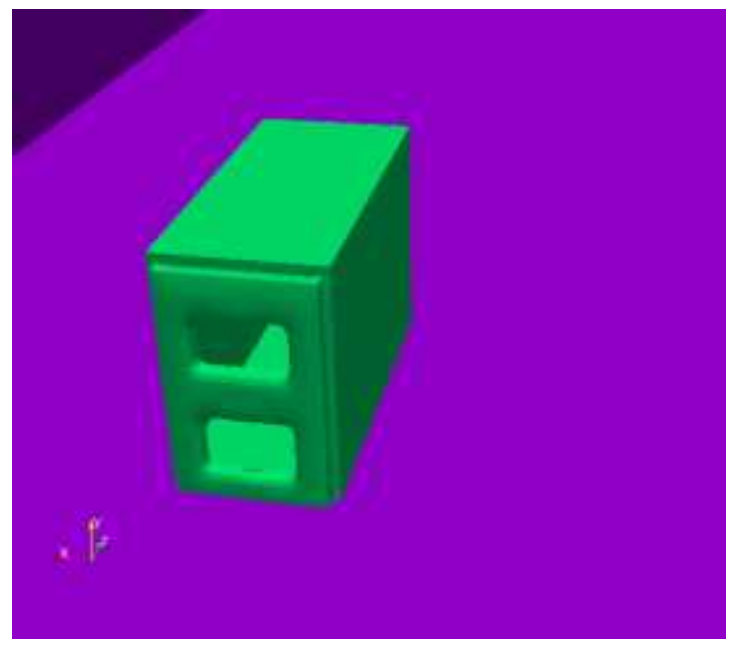

Figure 4: Case 4(Double Single Sided Ventilation)

The CFD simulation was performed at full scale. The computational domain were adopted as per COST guideline by [8]

For each single building, a dimension of $5 \mathrm{H}$ was used as the distance between the top and windward wall of the CFD model to the computational domain. Where $\mathrm{H}$ represents the Room Height.

For the lateral boundaries, a dimension of $2.3 \mathrm{H}$ was adopted as the horizontal distance between the sidewall of the room model to the computational domain.

Lastly, for the outflow boundaries, a distance of $15 \mathrm{H}$ between the leeward walls of the room model and the computational domain was considered..

\subsection{Boundary Condition}

At the inlet, the vertical profile is described by the logarithmic law

$$
u_{z}=\frac{\mathrm{u}_{\mathrm{ABL}}^{*}}{\kappa} \operatorname{In}\left(\frac{Z+Z_{0}}{Z}\right)-------(1)
$$

Where $(\kappa)$ is the von Karman's constant and $\mathrm{u}_{\mathrm{ABL}}^{*}$ is the frictional velocity 
In order to determine the turbulence kinetic energy $\left(k_{(z)}\right)$ and dissipation energy $\left(\varepsilon_{(z)}\right)$ according to formulae by [8],

$$
\begin{gathered}
k_{(z)}=\frac{\mathrm{u}_{A B L}^{2}}{\sqrt{ } C_{\mu}}--------(2) \\
\varepsilon_{(z)}=\frac{\mathrm{u}_{A B L}^{*^{3}}}{\kappa\left(z+z_{0}\right)}--------(3)
\end{gathered}
$$

Where $C_{\mu}$ is an empirical constant taken as $0.0845, z_{0}$ is the aerodynamic roughness length.

For the ground, a rough wall boundary condition was imposed. According to [9], in open foam CFD codes, the logarithmic law with sand grain roughness parameter $K_{s}$ is expressed as follows:

$$
\frac{u_{p}}{u^{*}}=\frac{1}{k} \operatorname{In}\left(\frac{\in z_{p}^{+}}{c_{S} K_{S}^{+}}\right)----------(4)
$$

Where $u_{p}$ is the tangential component of velocity vector at a near wall node and $C_{S}$ is a roughness constant which is set to ensure first matching order between the law of the wall and the inlet profile condition, $\in$ is a smooth constant.

$$
C_{s}=\frac{\epsilon z_{0}}{K_{S}}-----(5)
$$

For this analysis, $K_{S}=20 z_{0}$

Symmetry boundary condition was imposed at the lateral and top boundary.

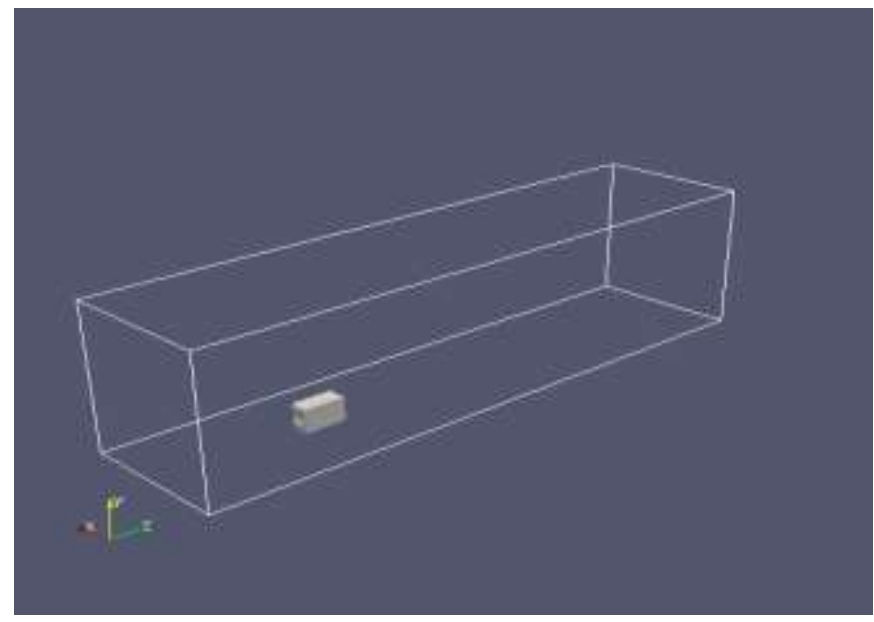

Figure 5: Computational Domain

\subsection{Solver Setting}

The commercial code SIMFLOW was used to solve the 3D steady RANS equations with the RNG-KE Turbulence model [10]. [11], studied indoor ventilation using eight different turbulence model and concluded that the RNG-KE turbulence model performed best. The simple algorithm was used for pressure velocity coupling. Second order discritization scheme was used for the viscous term and convective term of the governing equation. The concentration of $\mathrm{CO}_{2}$ species in the air within each room was modelled as a passive scalar $(\varphi)$ transport into the convection-diffusion equation in the form:

$$
\partial \varphi \partial t+\nabla \cdot(\cup \varphi)=\nabla \cdot(D \nabla \varphi)+S \varphi-------(6)
$$

Where, $\mathrm{U}$ is velocity obtained from the momentum equation, $\mathrm{D}$ is diffussity coefficient and $S \varphi$ is the source term.

In order to access convergence of a solution, both the scaled residue and the wind speed in some selected point of the computational domain was monitored as a function of the number of iteration. For cases 1, 2 and 3, Convergence was observed when the scaled residuals reached a minimum of $10^{-6}, 10^{-4}, 10^{-4}$ for $\mathbf{x}-, \mathbf{y}$ - and $\mathbf{z}$-velocity, $10^{-5}$ for $\boldsymbol{k}$ and $10^{-6}$ for $\boldsymbol{\varepsilon}$ respectively. For case 4 Convergence was observed when the scaled residuals reached a minimum of $10^{-4}, 10^{-5}, 10^{-6}$ for $\mathbf{x}-, \mathbf{y}$ - and $\mathbf{z}$-velocity, $10^{-5}$ for $\boldsymbol{k}$ and $10^{-6}$ for $\boldsymbol{\varepsilon}$ 


\section{International Journal of Engineering Research and}

Advanced Technology (IJERAT)

DOI: 10.31695/IJERAT.2021.3602

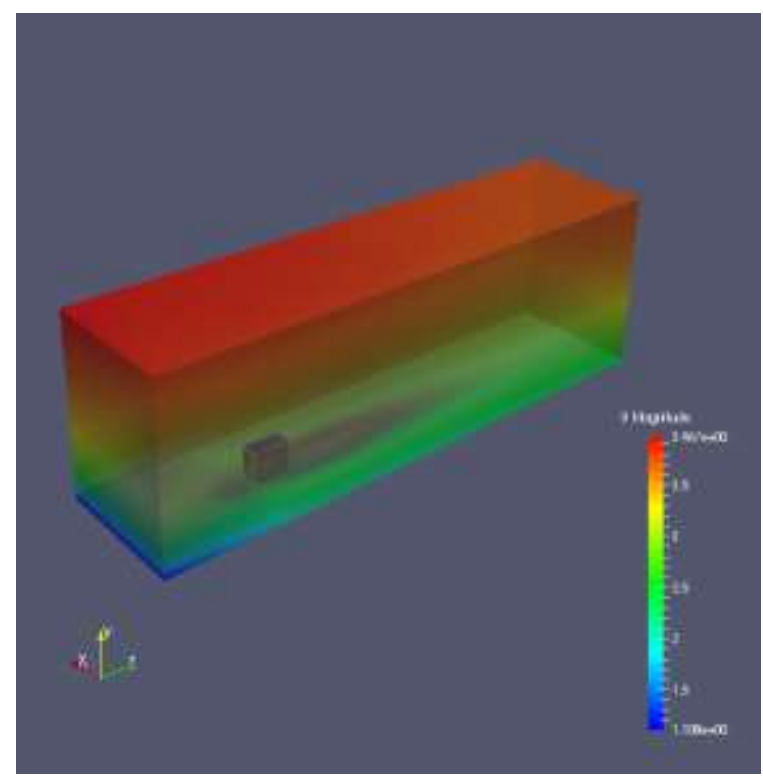

Figure 6: CFD visualization of the wind around the room model

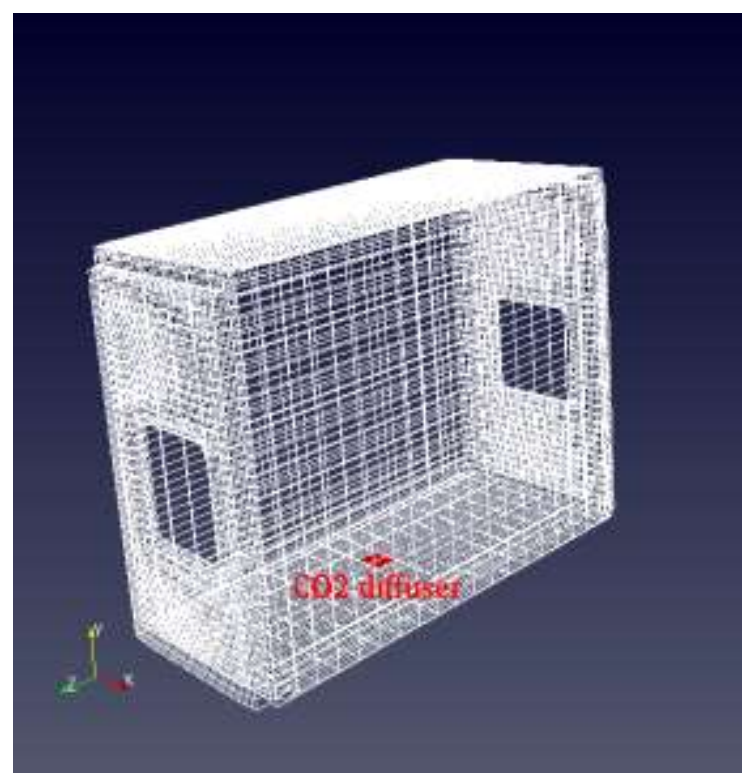

Figure 7: Room Model showing the $\mathrm{CO}_{2}$ diffuse

\section{RESULT AND ANALYSIS}

\subsection{Case 1: Single Sided Ventilation}

Single side ventilation is bidirectional airflow through a single opening. According to [12], the net airflow rate across an opening in single sided ventilation is zero. In order to maintain comfort within the room, Reference [13] recommends that air velocity onto people should not normally exceed 0.15 to $0.2 \mathrm{~m} / \mathrm{s}$ depending on air temperature and turbulence intensity. The air speed recorded at the head level $(1.8 \mathrm{~m})$ for an occupant standing at the centre of the room for this ventilation case was $0.07 \mathrm{~m} / \mathrm{s}$. This value reduces the risk of occupants experiencing local draft in a single sided ventilated room but may experience a higher percentage of pollutant concentration than other natural ventilation cases. According to [14], $\mathrm{CO}_{2}$ concentrations below $1000 \mathrm{ppm}$ are recommended to avoid discomfort in form of drowsiness and headache.

As can be observed in the $\mathrm{CO}_{2}$ contour diagram below, the $\mathrm{CO}_{2}$ pollutants were localised in most part of the room in larger concentration at values greater than 1000ppm.

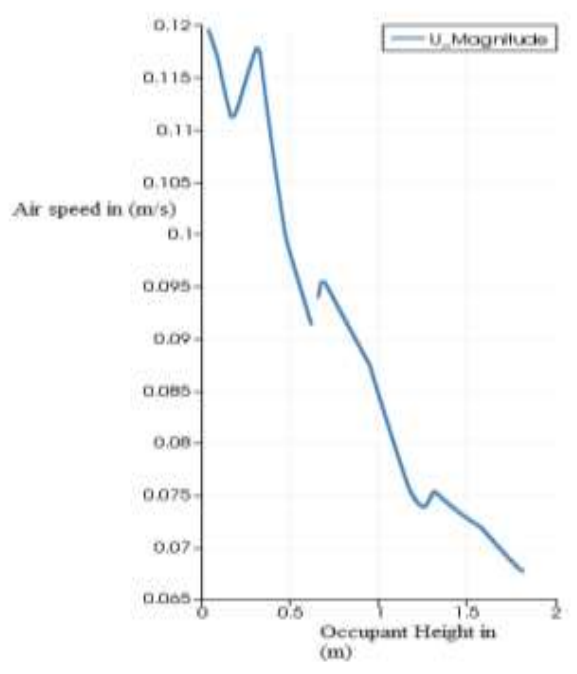

Figure 8: Velocity plot of air speed on occupant at the center of the room

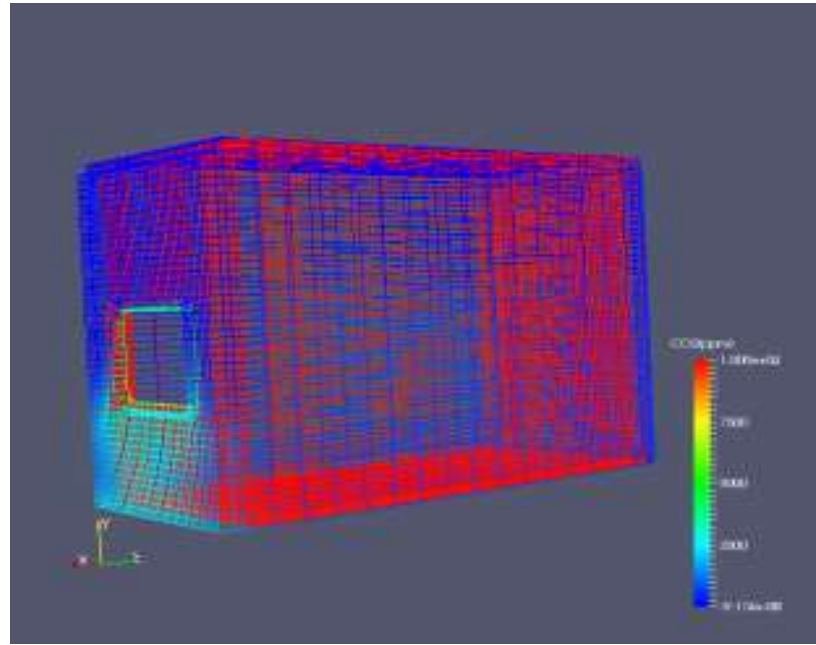

Figure 9: $\mathrm{CO}_{2}$ concentration in the room model 
Ideally air flow from one corner or a set of openings in cross ventilation is unidirectional. The main driving force in a naturally cross ventilated room is the difference in mean static pressure caused by the wind effect between the indoor and outdoor environment [12].

The diagram below shows that occupants within a cross ventilated room will have a higher risk of experiencing discomfort in terms of local draft. The ankle $(0.1 \mathrm{~m})$, elbow $(0.6)$ and ankle region $(1.8 \mathrm{~m})$ recorded air speeds higher than the recommendations as per [13].

However, the CFD analysis showed that cross ventilation is very efficient in controlling cases relating to pollutant dispersion. As the post processing result suggest below almost every part of the cross ventilated room recorded $\mathrm{CO}_{2}$ concentration values which are within the acceptable limits for indoor air quality (IAQ) as per [14].

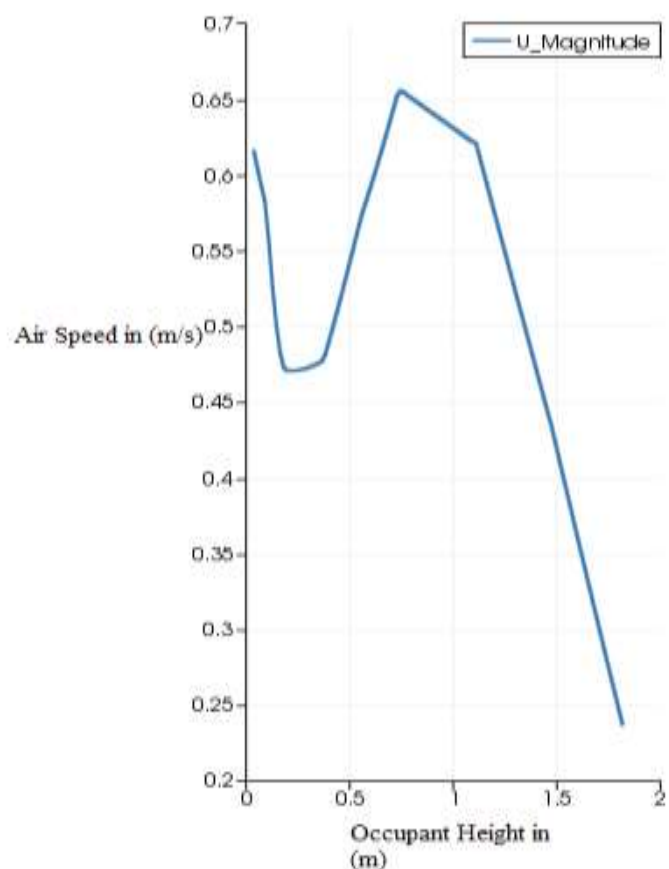

(m)

Figure 10: Velocity plot of air speed on occupant at the centre of the room

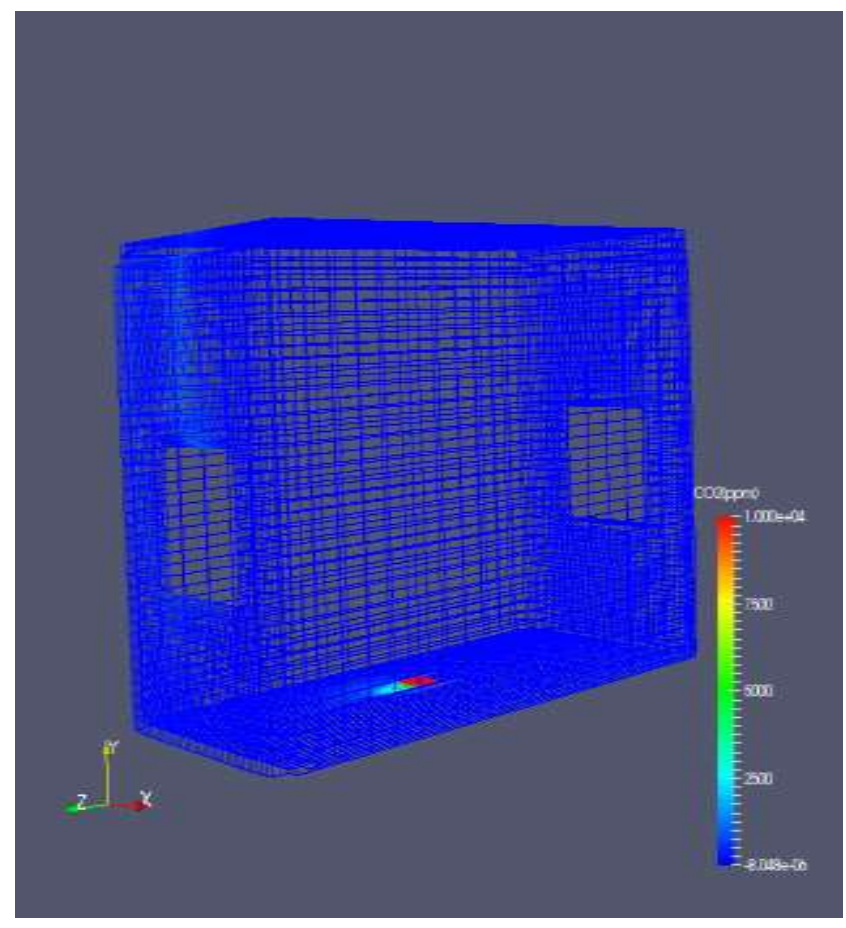

Figure 11: $\mathrm{CO}_{2}$ concentration in the room model

\subsection{Case 3: Bernoulli and Cross Ventilation}

Bernoulli principle is a kind of passive ventilation that uses pressure differences to exhaust air out of the room.

Just like in the cross ventilation, Bernoulli's principle uses wind speed to move air. It is generally known in the field of aerodynamic that wind in the free stream is less affected by wall shear stress and thus have lower pressure. In contrast to the No slip condition. These lower pressures of the wind can help suck fresh air through the building.

From the chart below it can be deduced that the value of air speed unto occupants in case 3 were higher than the recommended value for thermal comfort as stipulated in [13]. Thereby increasing probability of the occupant being dissatisfied with the office room air, with the sensation of air draft.

Also, the CFD result of pollutant dispersion for the case 3 showed that levels of $\mathrm{CO}_{2}$ concentration in the breathing zone of the room were within the range of acceptable standard for Indoor Air Quality. Although cross ventilation (Case 2) showed greater efficiency in improving the indoor air quality in terms of pollutant control and dispersion 


\section{International Journal of Engineering Research and Advanced Technology (IJERAT)}

DOI: 10.31695/IJERAT.2021.3602

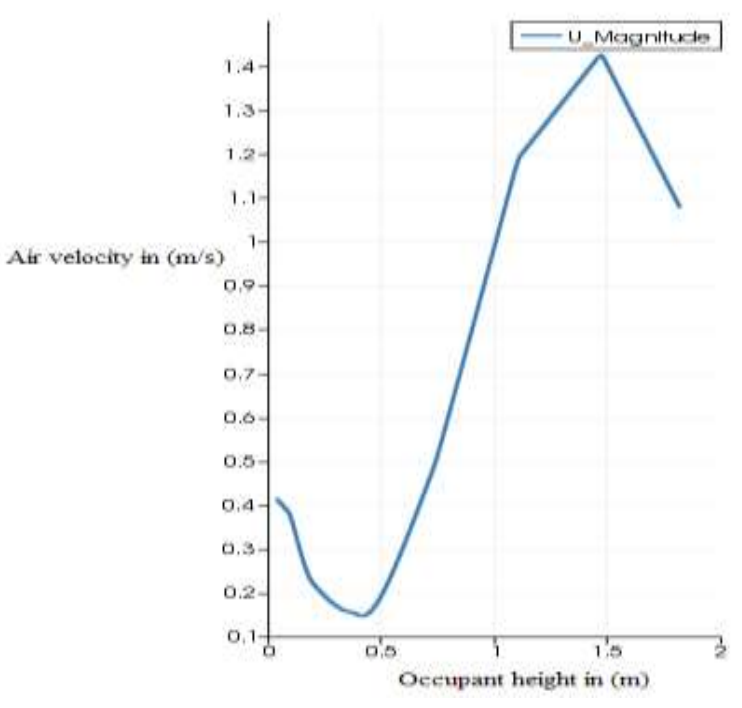

Figure 12: Velocity plot of air speed on occupant at the centre of the room

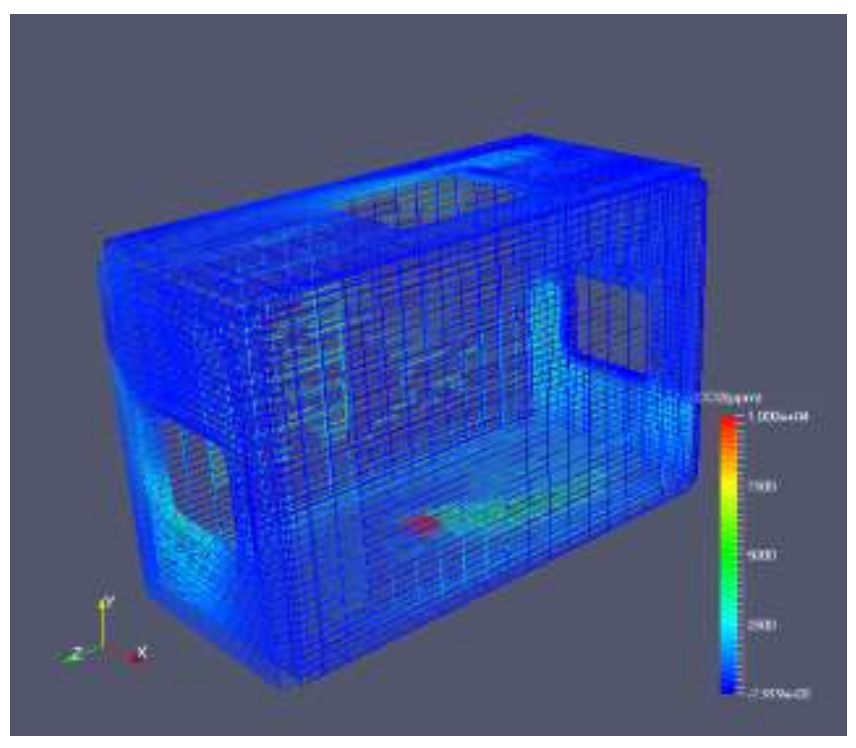

Figure 13: $\mathrm{CO}_{2}$ concentration in the room model

\section{Case 4: Double Single-Sided Ventilation}

An advancement of the single sided ventilation provides double single sided ventilation which is considerably more efficient.

Case 4 shows optimum air speed at the ankle and head level of the room occupant except at the elbow level where few occupants of the room may experience mild discomfort in form of local draft. The result of the pollutant dispersion relating to $\mathrm{CO}_{2}$ concentration of the room in case 4 showed lower level of $\mathrm{CO}_{2}$ pollutants than observed in the single sided ventilation case (case1).

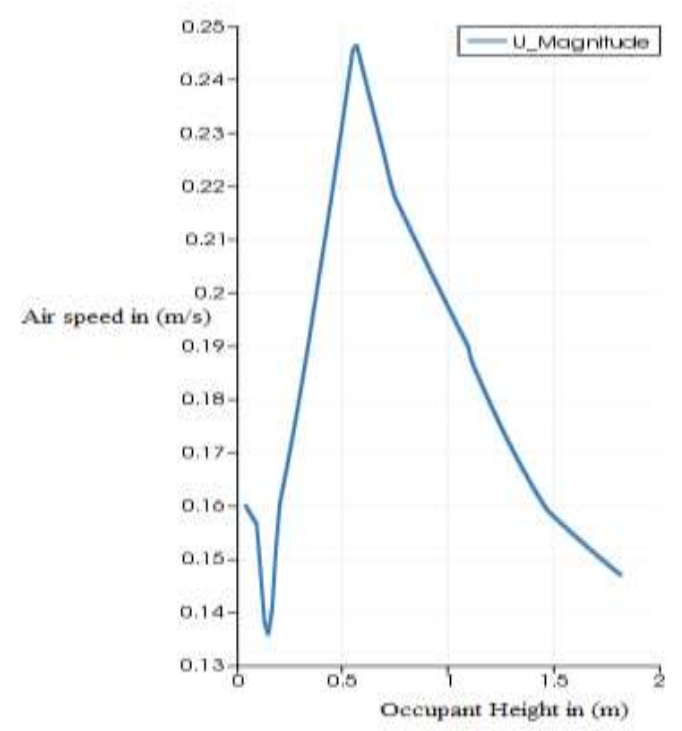

Figure 14: Velocity plot of air speed on occupant at the centre of the room

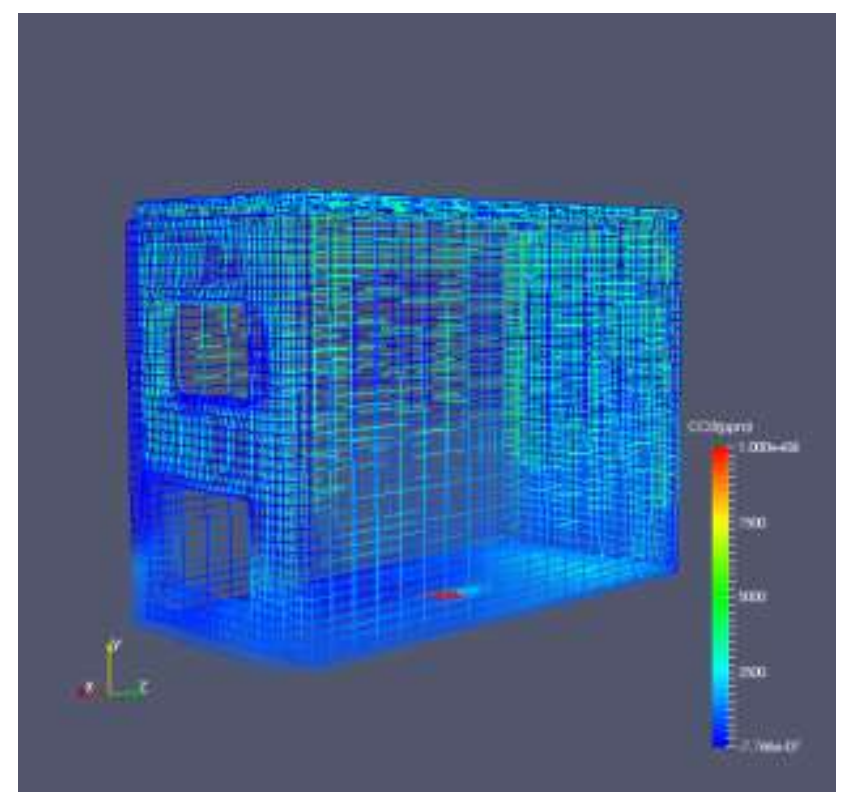

Figure 15: $\mathrm{CO}_{2}$ concentration in the room model 


\section{CONCLUSION}

The study analysed CFD simulations of wind-driven Natural ventilation of a typical room model. The RNG-KE turbulence model was employed to close the 3D steady state Reynolds Averaged Navier Stokes Equation of the fluid flow. Both the outdoor wind flow and indoor airflow were solved simultaneously within the same computational domain. The CFD simulation focused on different kinds of wind-driven natural ventilation strategies of a room model.

The intension of the study was in two folds:

1. To study the airflow pattern and air speed unto occupants within the room spaced

2. To determine the level of pollutant dispersion for all analysed Natural ventilation strategies

First, Case 1 and Case 4 showed a reduce level of air draft $(\mathrm{V}<0.2 \mathrm{~m} / \mathrm{s})$ within the room unlike the Case 2 and Case 3 where the air speed on the room occupants most especially at the ankle and head region were much higher than that recommended as per [13].

Secondly, Case 2 showed greater efficiency in dealing with pollutant dispersion then followed by Case 3 and Case 4 respectively.

The $\mathrm{CO}_{2}$ concentrations in almost every part of the room for Case 2 were well within the acceptable range recommended for human occupancy as per [14].

The author however concludes that in terms of wind-driven natural ventilation, Case 4 can be a more efficient strategy in providing both thermal comfort and IAQ for occupants within a single room.

\section{REFERENCES}

[1]. T.S. Larson and P.Heiselberg. "Single-sided Natural Ventilation Driven by a combination of wind pressure and temperature difference". Energy Build 40(60). 1031-104.2007.

[2]. Energy Information Administration, State Energy Data Report 1995,Table 3 through 7,1995.

[3]. Energy consumption Guide 19, Energy efficiency in offices, Energy Efficiency office/HMSO, London, 1993.

[4]. M.Mendell and A. Smith. "Consistent pattern of elevated symptoms in air-conditioned offices: a reanalysis of epimiologycal studies". American Journal of Public Health, Volume 80, PP. 57-68.1990.

[5]. S.Burge, P.Jones and A. Robertson. "Sick building syndrome"., International conference on indoor Air Quality and climate. Ottawa, Ontario .1990.

[6]. C.Alloca, Q.Chen and L.R.Glicksman. "Design analysis of single sided natural ventilation" Energy and Building 35(8), 785-795. 2003.

[7]. Q.Chen. "Ventilation performance prediction for buildings: A method overview and recent applications" Build Environ 44(4), 848-858. 2009.

[8]. J.Franke, A.Hellsten, H.Schlunzen, B.Carrissimo. "Best practice guidelines for the CFD simulation of flows $\mathrm{n}$ urban environment". COST 732: quality assurance and improvement of micro scale meteorological models. Cost office Brussel, ISBN 3-00-018312-4.2007.

[9]. C.V. Okafor, P.E. Ogunoh, J.U. Ezeokonkwo and D.A. Obodoh. “Atmospheric Boundary Layer Simulation Using Wall Function Approach in Openfoam CFD Software". European journal of Engineering Research and science volume 3, NO 2, PP 1-6.2018.

[10]. V.Yakhot, S.Orszag, S.Thangam, T.Gatski and C.Speziale, "Development of turbulence model for shear flows by a double expansion technique”. Physics of fluids. [Online].4(7), pp1510-1520.1992. 
[11]. Q. Chen. "Comparison of different K-E models for indoor airflow computations", Numerical Heat Transfer 28(B) 353369.1995 .

[12]. I, Ahsan, V.N.Peter, G.Amalie and A. Alireza. "Single sided Natural Ventilation through a centre-pivot roof window" Proceedings Journal of Air.2014

[13]. BS EN ISO 7730.1995.Moderate thermal environments-determining of the PMV and PPD indices and specification of the conditions for the thermal comfort. British standards Institute, London.

[14]. BS EN ISO 7730.2005.Ergonomics of thermal environments-Analytical determination and interpretation of thermal comfort using calculation of PMV and PPD indices and local thermal comfort criteria. International organization for standardization (ISO), Geneva. 